\title{
FORMAÇÃO DE PROFESSORES DE MATEMÁTICA E OS CONHECIMENTOS NECESSÁRIOS À DOCÊNCIA COM TECNOLOGIAS DIGITAIS
}

\author{
MATHEMATICS TEACHER EDUCATION AND THE NECESSARY KNOWLEDGE TO \\ TEACH WITH DIGITAL TECHNOLOGIES

\section{FORMACIÓN DE PROFESORES DE MATEMÁTICAS Y EL CONOCIMIENTO NECESARIO PARA LA ENSEÑANZA CON TECNOLOGÍAS DIGITALES}

\author{
Nielce Meneguelo Lobo da Costa \\ ${ }^{1}$ Universidade Anhanguera de São Paulo, São Paulo, Brasil \\ Recibido: 30/01/2021 - Aceptado: 13/06/2021 - Publicado: 01/12/2021 \\ Remita cualquier duda sobre esta obra a: Nielce Meneguelo Lobo da Costa. \\ Email:nielce.lobo@gmail.com
}

\begin{abstract}
RESUMO
O objetivo deste texto é o de promover reflexôes sobre o papel que as Tecnologias Digitais da Informação e Comunicação (TDIC) têm desempenhado na formação docente, bem como no ensino de Matemática. A discussão se baseia nas pesquisas empreendidas pelo grupo de pesquisa ao qual pertenço, sob três perspectivas: integração de tecnologias ao ensino; conhecimentos e competências necessárias à docência em Matemática com tecnologia digital; processos formativos que favorecem o desenvolvimento profissional. Tais pesquisas têm sido focadas na formação inicial e continuada de professores. As bases teóricas que nos têm subsidiado tanto a investigar a base de conhecimentos e as competências necessárias ao professor de matemática para ensinar utilizando tecnologias digitais, quanto a pesquisar processos formativos que favoreçam a construção de conhecimentos pelos docentes, vêm dos estudos sobre: 1) conhecimento profissional docente e conhecimento pedagógico e tecnológico do conteúdo (TPACK), 2) processos de apropriação e apropriação tecnológica, 3) gênese instrumental, 4) competência digital e 5) professional noticing (olhar profissional ou mirada profesional). No texto listamos as pesquisas empreendidas e discutimos as bases teóricas que as subsidiaram, apresentando o que concluímos até o presente.
\end{abstract}

Palavras-chave: Competência e Conhecimento; TPACK; Competência digital; Apropriação digital. 


\begin{abstract}
This paper aims to promote reflections on the role that Digital Information and Communication Technologies (DICT) have played into mathematics teachers' education, as well as in Mathematics teaching. The discussion is grounded in research undertaken by the author on three perspectives: technology integration applied to teaching, knowledge and competence required for teaching using technology, and formative processes that favour the construction of knowledge by teachers. Such studies have been focused on initial and continuing teacher education. The theoretical foundation that has subsidized the investigation mentioned above, come from studies as follows: 1) professional knowledge and technological pedagogical content knowledge (TPACK), 2) processes of appropriation and technological appropriation, 3) instrumental genesis, 4) digital competence and 5) professional noticing (olhar profissional or mirada profesional). The paper comprises a list of research undertaken by the author's research group, discusses the theoretical foundation that subsidized it, and presents takeaways until the present moment.
\end{abstract}

Keywords: Competence and Knowledge; TPACK; Digital Competence; Digital Apropriation.

\title{
RESUMEN
}

El objetivo de este trabajo es promover reflexiones sobre el papel que las Tecnologías Digitales de la Información y Comunicación han desempeñado en la formación docente, así como en la enseñanza de las Matemáticas. Para ello, se realiza una discusión basada en las investigaciones del grupo de trabajo al que pertenezco, que han venido conduciéndose en la formación inicial y continua de profesores desde tres perspectivas: (a) integración de tecnologías para la enseñanza; (b) conocimiento y competencias necesarias para la docencia en Matemáticas con tecnologías digitales; $y$ (c) procesos formativos que favorecen el desarrollo profesional. Las bases teóricas que nos han subsidiado para investigar tanto la base de conocimiento y las competencias necesarias del profesor de matemáticas para enseñar utilizando tecnologías digitales, como los procesos formativos que favorezcan la construcción de conocimiento por los docentes, provienen de los estudios sobre: (a) conocimiento profesional docente y conocimiento pedagógico y tecnológico del contenido; (b) procesos de apropiación y apropiación tecnológica; (c) génesis instrumental; (d) competencia digital; y (e) professional noticing (mirada profesional). En el trabajo se listan las investigaciones realizadas y se discuten las bases teóricas que las subsidiaron, presentando lo que hemos concluido hasta la actualidad.

Palabras clave: Competencia y Conocimiento; TPACK; Competencia digital; Apropiación digital.

\section{INTRODUCCIÓN}

A jornada que tem sido trilhada pelos educadores para integrar as tecnologias digitais de informação e comunicação (TDIC) aos processos de ensino e de aprendizagem tem quase quarenta anos. Desde os longínquos anos 1980 quando os computadores foram entrando mais intensamente nas empresas, na sociedade e sendo paulatinamente inseridos nas escolas, várias foram as conquistas e os acertos, mas também os fracassos e os enganos, na tentativa de auxiliar o aprendizado dos estudantes fazendo uso de tecnologia digital.

A integração de tecnologia ao ensino é um processo complexo que envolve diversas esferas de atuação educacional. Desde políticas públicas de gestão para viabilizar a infraestrutura elétrica, eletrônica e de internet, até a escolha dos materiais e dos recursos mais adequados à cada situação de ensino e, não 
menos importante, a determinação da metodologia de utilização, que envolve a elaboração de tarefas e atividades que possam se beneficiar das particulares tecnologias envolvidas.

No cenário do século XXI, com a modificação dos hábitos e das demandas intelectuais, com a valorização do pensamento flexível, da expertise e da comunicação complexa, é fundamental que o sistema educacional se prepare para formar indivíduos que tenham autonomia para a busca e seleção de informações, a tomada de decisão e a solução de problemas para a sociedade. A evolução tecnológica nos ensina que a memorização de fatos e conceitos, assim como a capacidade de reprodução de procedimentos e de algoritmos pelos alunos, tão valorizadas tradicionalmente nas escolas do século XX, hoje deixam de estar no centro das preocupações, uma vez que tais tarefas podem ser feitas por máquinas. A valorização está no pensamento independente, bem fundamentado, em acordo com o contexto e na competência de aprender constantemente inovando ao se deparar com situaçóes inusitadas.

Assim sendo, o ensino de Matemática necessita passar por transformações para se adequar às novas necessidades dos aprendizes e aos objetivos educacionais. Isso significa rever currículos, prioridades, metodologias e métodos. A prática de ensino de Matemática precisa ser remodelada considerando os novos rumos e as várias possibilidades metodológicas viabilizadas pelos recursos tecnológicos digitais disponíveis.

Nesse ponto, chega-se à questão do professor -ou do grupo de professores- que vai gestar o processo de ensino e, em particular, o ensino da Matemática. Se faz necessário definir como preparar esse professor e quais são os conhecimentos e as competências que esses precisam ter para ensinar com as tecnologias digitais. Essas são questões centrais quando se pensa na Educação do Professor de Matemática (EPM), seja ela no nível inicial (de Graduação, a Licenciatura que antecede o serviço: preservice) ou no nível da Educação Continuada (ao longo da profissão ou em serviço: in-service), pois é inegável a necessidade de estratégias formativas para propiciar o desenvolvimento de conhecimentos e competências para a docência nos professores e nos futuros professores.

Ensinar com as TDIC é desafiador para os professores e exige a construção de novos conhecimentos e o desenvolvimento de competências que lhes permitam inserir adequadamente tais tecnologias na sala de aula e integrá-las aos conteúdos curriculares. Nesse processo de integração é fundamental que sejam exploradas as potencialidades das TDIC para a construção de conceitos e dos conhecimentos matemáticos pelos alunos. Vale ressaltar que, em várias das escolas dos mais diversos níveis de ensino (Básico ou Superior), "o uso das tecnologias para ensinar frequentemente se presta para ilustrar o conteúdo curricular e "modernizar" a aparência sem, contudo, modificar a essência do ensino"1 (Lobo da Costa et al., 2017, p. 236, tradução livre da autora). Assim, a aula continua se desenvolvendo da forma tradicional, muitas vezes centrada no professor, com pequena participação do aluno, com

\footnotetext{
1 "the use of technologies for teaching often serves for curriculum content illustration and "modernization" appearance without, however, modifying the teaching essence".
} 
instruções diretivas e tarefas elaboradas para treino de procedimentos e técnicas. Um aspecto fundamental do ensino de matemática com tecnologia digital está em levar o aluno a aprender a pensar com a tecnologia, entendida aqui como uma forma para a estruturação do pensamento.

Ao integrar as TDIC nos processos educacionais, entendemos que para os professores elas estão ligadas ao fazer pedagógico e o foco do professor está em utilizar as tecnologias para se comunicar e desenvolver conteúdos curriculares, ou seja, o seu foco está no processo de ensino, enquanto para o aluno estão ligadas ao seu modus operandi como nativo digital -integrante da Geração $Z^{2}$; o foco está em utilizar as tecnologias como uma ferramenta para auxiliar a compreensão do mundo e, em particular, da Matemática, ou seja, o foco para o aluno está na aprendizagem.

A partir dessas considerações, o objetivo deste texto é o de promover reflexóes sobre o papel que as TDIC têm desempenhado na formação docente e no ensino de Matemática, a partir das pesquisas que temos empreendido sobre integração de tecnologias ao ensino; sobre os conhecimentos e habilidades requeridas para ensinar usando tecnologia e sobre processos formativos que favorecem o desenvolvimento profissional, tanto na formação inicial quanto na continuada. Entendemos, seguindo Ponte (1998), o desenvolvimento profissional como um processo interior ao docente e que inclui a formação da sua identidade de professor, as habilidades, os valores profissionais, as atitudes e os conhecimentos.

\section{PESQUISAS EMPREENDIDAS NA FORMAÇÃO DO PROFESSOR DE MATEMÁTICA E INTEGRAÇÃO DE TECNOLOGIA DIGITAL À PRÁTICA}

As pesquisas que temos desenvolvido nos últimos vinte anos têm sido focadas na formação inicial e continuada de professores, particularmente objetivando investigar a integração de tecnologia digital para desenvolver o currículo de matemática. $\mathrm{Na}$ formação inicial temos investigado aprendizagem profissional para uso de tecnologia e, na formação continuada, investigado a docência de matemática na Educação Básica para o uso de tecnologia digital integrada ao currículo. Além dessas, temos empreendido pesquisas sobre as políticas públicas de formação docente para o uso de tecnologia digital no ensino de Matemática.

Podemos agrupar as pesquisas empreendidas em três conjuntos dependendo do tipo de formação (inicial ou continuada), do contexto de desenvolvimento da pesquisa e do segmento de ensino impactado. O primeiro conjunto refere-se à Formação inicial do professor de Matemática, desenvolvida em Cursos de Graduação, Licenciatura em Matemática -nível de Ensino: Superior e com foco na aprendizagem profissional.

\footnotetext{
2 Prensky (2010) designou os indivíduos nascidos a partir de 1995 de "nativos digitais”, constituindo uma "Geração Z”, de "zap" = "energia” e rapidez em tudo que faz. Essas pessoas, que vivem desde o início em uma sociedade impregnada de tecnologias digitais, têm seu aprendizado alterado em relação ao das gerações anteriores, com estruturas cerebrais diferentes, mais rápidas, desempenhando tarefas simultâneas e com procedimentos distintos dos de estudantes de outras épocas.
} 
Nesse conjunto está a pesquisa de doutoramento de Figueiredo (2015), que investigou o ensino de trigonometria na disciplina de Matemática Elementar com graduandos do primeiro ano do curso e utilizou os softwares GeoGebra e Graphmatica, entre outros recursos didáticos. Além dessa pesquisa, está em andamento a pesquisa de doutoramento de Nonato, orientada por nós, que investiga como cursos de formação inicial de professores de Matemática de universidades públicas do Estado do Mato Grosso do Sul (Brasil) têm propiciado aos licenciandos oportunidades de aprendizagem das TDIC para ensinar (para detalhes ver Nonato \& Lobo da Costa, 2020a, 2020b).

O segundo conjunto de pesquisas refere-se à Formação continuada do professor de Matemática, que impacta a Educação Básica (Ensino Fundamental e Médio) e com foco no desenvolvimento profissional docente. Quanto ao contexto de desenvolvimento dessas pesquisas, elas se localizam em três subgrupos: (a) pesquisas orientadas envolvendo grupos de professores e tecnologia educativa, com o processo formativo ocorrendo na escola; (b) pesquisas orientadas envolvendo parcerias estabelecidas entre a universidade e diretorias estaduais de ensino da Secretaria de Educação do Estado de São Paulo (SEESP), com a formação sendo desenvolvida nos espaços formativos das diretorias de ensino; e (c) pesquisas também advindas de parcerias entre a universidade e diretorias estaduais de ensino da SEESP, com a formação continuada sendo desenvolvida na escola.

No subconjunto (a) estão as pesquisas de Marchi (2011), Orfão (2012) e Vieira (2013). Marchi (2011) investigou com o grupo de professores o ensino de Geometria euclidiana (seção áurea) utilizando a metodologia de Webquest. Orfão (2012) com o grupo de professores investigou ensino de funções trigonométricas e utilizou o software GeoGebra e objetos de aprendizagem de repositórios livres. Vieira (2013) em sua pesquisa sobre um grupo de professoras da primary school analisou o processo de apropriação de tecnologia digital por elas ao estudarem e ensinarem figuras geométricas planas e espaciais.

No subconjunto (b) estão as pesquisas de Muraca (2011), Poloni (2015), Oliveira (2017), Pereira Filho (2018) e Silva (2018). Muraca (2011) pesquisou uma formação continuada na qual se abordou o ensino de Geometria Espacial de Posição com os softwares Cabri 2 e Cabri 3D. Poloni (2015) investigou uma formação continuada focada em discutir recursos didáticos para ensino de trigonometria e utilizou como tecnologia digital games e os softwares GeoGebra e Graphmatica. Oliveira (2017) investigou uma formação continuada que abordou situações de ensino articulando geometria e funções quadráticas. Pereira Filho (2018) investigou em uma formação continuada o ensino de Probabilidade por meio de aulas investigativas e utilizou os softwares Excel e GeoGebra. Silva (2018) investigou em uma formação continuada a integração de tecnologia digital para ensinar Poliedros utilizando o GeoGebra 3D.

No subconjunto (c) está a pesquisa de doutoramento da autora Lobo da Costa (2004), que envolveu professores que ensinam matemática nos anos iniciais de escolaridade. Nela foram investigados os fatores significativos do processo formativo para auxiliar o professor a utilizar o computador para a construção de práticas pedagógicas. O conteúdo foi o Tratamento da Informação e a Estatística e o software utilizado foi o de bancos de dados computacionais Tabletop. 
O último conjunto de pesquisas refere-se às políticas públicas brasileiras de integração de tecnologia ao currículo de Matemática na Educação Básica. No caso, pesquisas orientadas por nós sobre projetos de formação continuada empreendidos pela SEESP, tais como os intitulados Rede Aprende com a Rede; Projeto Aula Interativa e Projeto M@tmídias. Neste conjunto estão as pesquisas de Dias (2010), Oliveira (2014), Dias (2015) e Patriarca (2016). Neste texto o foco está na discussão referente ao grupo de pesquisas listadas nos conjuntos 1 e 2.

A partir desse panorama, discute-se a seguir a fundamentação teórica utilizada para subsidiar tais pesquisas e o que aprendemos ao longo deste caminho. As pesquisas desenvolvidas sobre formação de professores, especialmente para o caso do docente de Matemática e com uso de tecnologias, têm se assentado sobre bases teóricas apresentadas brevemente na próxima seção.

\section{CONHECIMENTOS E COMPETÊNCIAS DOCENTES: BASES TEÓRICAS}

Ao longo do tempo, o arcabouço teórico que nos tem subsidiado a investigar os conhecimentos e as competências necessárias ao professor de matemática para ensinar utilizando tecnologias digitais e a pesquisar sobre como podemos auxiliar essa construção de conhecimentos nos processos formativos docentes é constituído pelos estudos sobre:

- O conhecimento profissional docente, amparada principalmente na Teoria da Base de conhecimentos de Shulman $(1986,1987)$, nos estudos de seguidores dessa teoria e no modelo do conhecimento pedagógico e tecnológico do conteúdo (TPACK) desenvolvido por Mishra e Khoeler (2006);

- Os processos de apropriação e apropriação tecnológica, com base em Leontiev e nas pesquisas de Sandholtz et al. (1997), complementadas pelas de Puentedura (2013);

- A Gênese Instrumental, com base em Rabardel (1995, 1999);

- A competência digital, seguindo documentos europeus, tais como o: European Framework for the Digital Competence of Educators: DigCompEdu (https://ec.europa.eu/jrc/en/digcompedu) e The Digital Competence Framework for Citizens with eight proficiency levels and examples of use - DigComp2.1;

- O olhar profissional (mirada profesional em espanhol ou professional noticing em inglês), apoiando-nos nos estudos de Mason (2002) e de Llinares (2013).

A Figura 1 sintetiza essa dimensão teórica dos estudos. 


\section{Figura 1}

Bases teóricas para investigar conhecimentos e competências docentes

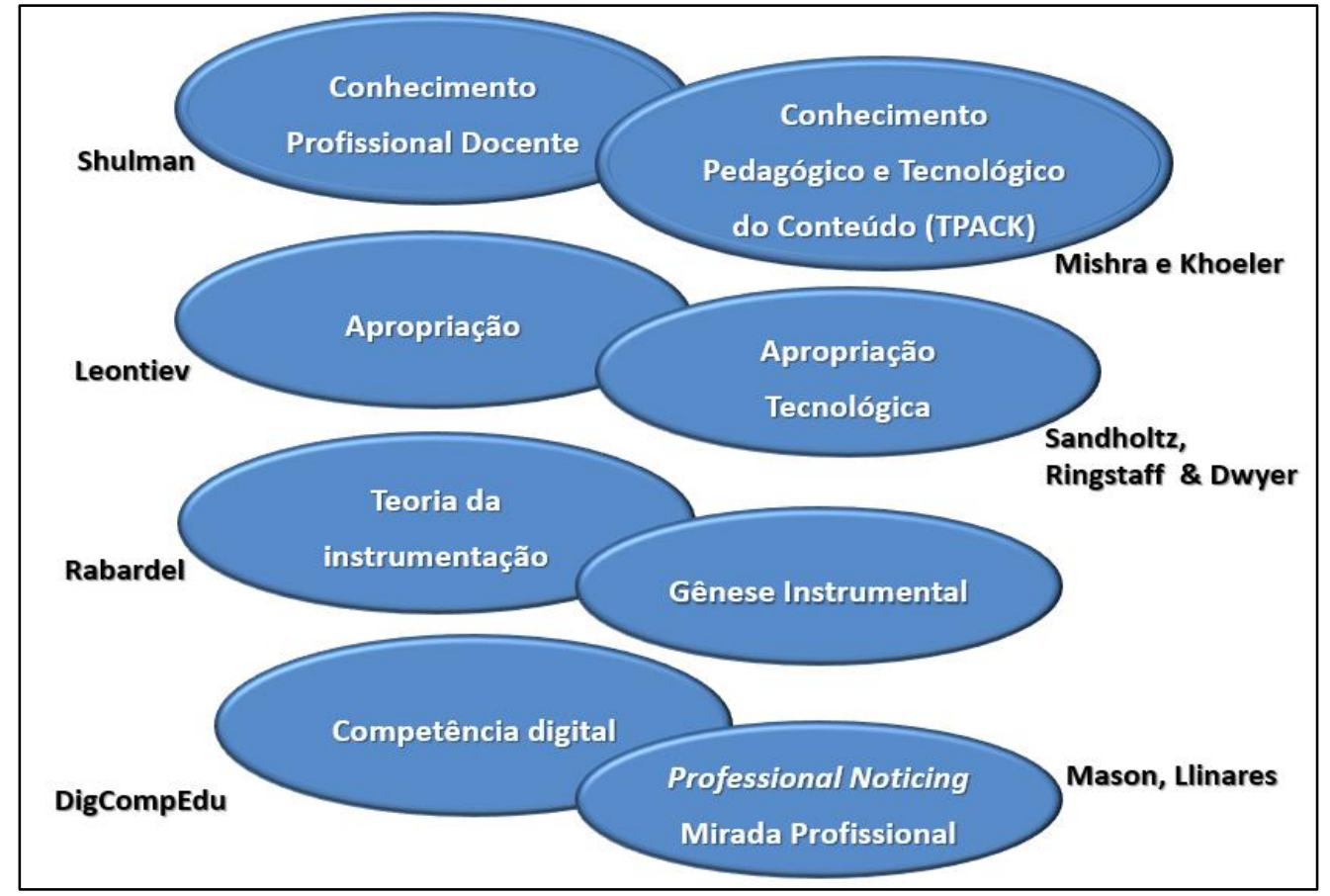

Passamos a seguir a discutir a Base teórica.

\section{CONHECIMENTO PRofissional DOCEnTE E CONHECIMENTO PEDAGÓGico TECNOLÓGICO DO CONTEÚdO}

Ao pesquisar sobre formação de professores, uma questão central diz respeito às maneiras de auxiliar o desenvolvimento profissional dos docentes, tanto na formação inicial quanto ao longo da carreira. O desenvolvimento profissional, como enfatiza Ponte (1998), é um processo interno do professor e dele faz parte o conhecimento profissional docente.

$\mathrm{Na}$ década de 1980, estudos pioneiros de Shulman levaram-no à formulação de uma teoria, intitulada por Knowledge Base Theory (KBT) (Shulman, 1986, 1987), na qual identificou a base de conhecimentos que um professor deve ter para ensinar e como tais conhecimentos devem se articular. $\mathrm{Na}$ KBT, o autor indicou como sendo necessários ao professor para ensinar: o conhecimento do conteúdo específico; o pedagógico geral; o do currículo a ser trabalhado; o pedagógico do conteúdo disciplinar; o dos alunos e de suas características cognitivas; o dos contextos educacionais; o dos fins, dos propósitos e dos valores educacionais. Esses conhecimentos foram por eles agrupados em três conjuntos: conhecimento do conteúdo específico; conhecimento curricular e conhecimento pedagógico do conteúdo.

Para Shulman $(1986,1987)$, o conhecimento do conteúdo específico é relativo ao objeto de estudo, o conhecimento curricular é o conhecimento que o professor deve ter sobre o currículo da disciplina, identificando o que o aluno aprendeu antes de estar no referido ano escolar e o que deverá 
aprender depois (conhecimento curricular vertical), além de conhecer o que este aluno está aprendendo em outras disciplinas (conhecimento curricular lateral). $O$ terceiro conjunto é o conhecimento pedagógico do conteúdo, que é construído constantemente pelo professor ao ensinar e enriquecido quando se amalgama com os outros tipos de conhecimentos. Ele é uma forma de conhecimento do conteúdo e inclui a compreensão do que significa ensinar um tópico de uma disciplina específica, assim como os princípios e técnicas que são necessários para tal ensino. A identificação desse tipo de conhecimento do professor representou na época uma inovação, uma vez que antes se considerava o conhecimento de pedagogia e de conteúdo como componentes dissociados em relação ao conhecimento dos professores.

A KBT foi um marco importante para as pesquisas sobre o professor e inspiraram diversos pesquisadores nas décadas posteriores. Com relação aos conhecimentos profissionais que os professores devem ter para usar a tecnologia digital para ensinar, diversos pesquisadores têm conduzido pesquisas e um dos destaques são os estudos de dois professores da Universidade de Michigan: Punya Mishra e Matthew Koehler. Eles desenvolveram, partindo dos estudos de Shulman, um Modelo contendo três conjuntos que se interceptam, representando a base de conhecimentos do professor para se ensinar com tecnologia. Os conjuntos simbolizados por diagramas de Venn representam: o conhecimento do conteúdo - no nosso caso o conhecimento matemático, o conhecimento pedagógico e o conhecimento tecnológico. O Modelo foi denominado de TPACK ${ }^{3}$ - Technological Pedagogical Content Knowledge, este é, o tipo de conhecimento que é mobilizado pelo professor para ensinar com tecnologia e ele está representado na intersecção dos três conjuntos, simboliza uma mescla que se destaca como uma forma emergente de conhecimento, que vai além de todos os seus componentes. Mishra e Koehler (2006). A Figura 2 simboliza os três conjuntos de conhecimentos de acordo com o Modelo TPACK.

\footnotetext{
${ }^{3}$ Inicialmente, os autores adotaram o acrônimo TPCK para o Technological Pedagogical Content Knowledge e mais tarde o renomearam para TPACK Technological Pedagogical AND Content Knowledge - que se pronuncia "tee-pack", dessa forma "soa" no inglês como sendo um "pacote total”, isto é, como um amálgama integrado dos três tipos de conhecimento: tecnológico, pedagógico e do conteúdo, os quais, então, produzem um novo tipo de conhecimento (Lobo da Costa et al., 2015).
} 


\section{Figura 2}

A base de conhecimentos para ensinar com tecnologia (Koebler e Mishra, 2009, p. 63)

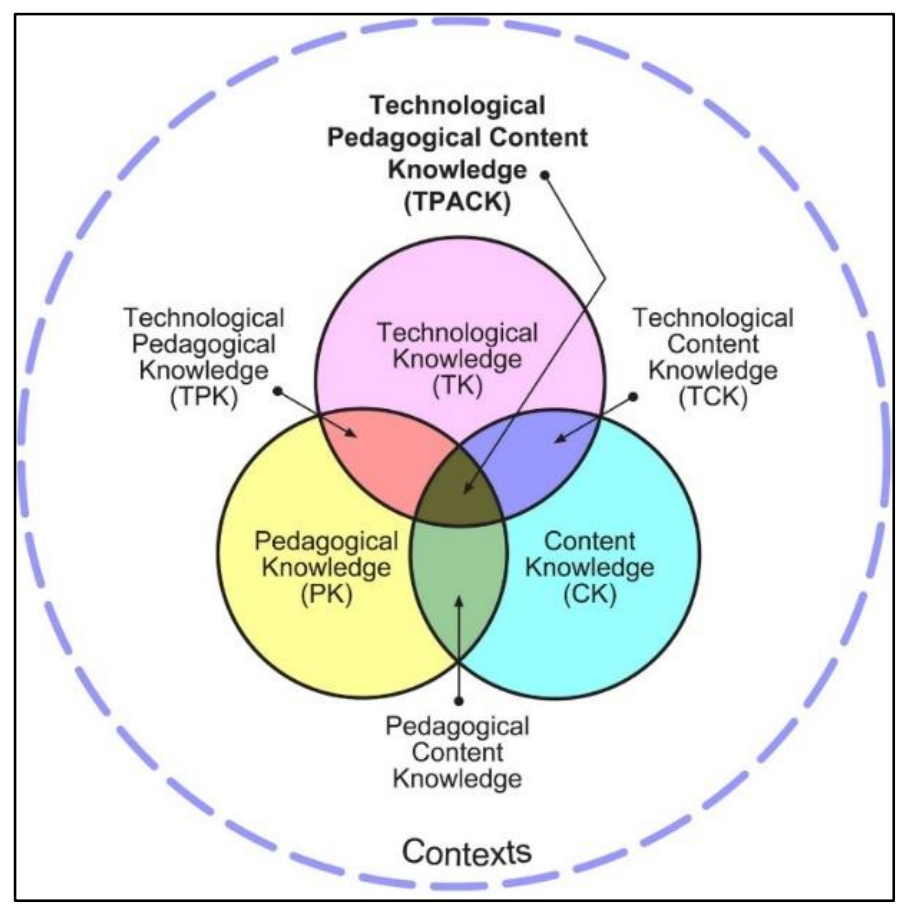

Para os autores, os conhecimentos tecnológicos, pedagógicos e do conteúdo se amalgamam gerando um novo tipo de conhecimento, que inclui a compreensão pelo professor: (a) sobre a representação de conceitos utilizando tecnologias; (b) das técnicas pedagógicas que usam as tecnologias de forma construtiva para ensinar conteúdos; (c) sobre o que faz com que alguns conceitos sejam difíceis e outros fáceis de aprender e sobre como a tecnologia pode auxiliar a enfrentar as dificuldades; (d) sobre as possibilidades de uso da tecnologia para o aluno construir conhecimentos; (e) sobre os conhecimentos prévios dos alunos em cada conteúdo a lecionar; e (f) sobre as teorias epistemológicas.

Os processos didáticos ligados à prática docente, quais sejam: o planejamento -que inclui selecionar, conceber e elaborar recursos e atividades para o ensino e a aprendizagem -, de implementação -que envolve a instrução propriamente dita- e de avaliação -que envolve acompanhar a aprendizagem e obter dados sobre os resultados alcançados; são processos sustentados pelos "conhecimentos sobre a tecnologia incorporados nas oportunidades de desenvolvimento profissional, que transcendem o mera experiência prática...” (Prieto \& Ortiz, 2019, p. 10).

Como formadores de professores e, também, como pesquisadores na área da formação docente, nos interessa investigar como dar suporte aos professores e auxiliá-los a construir o TPACK. Para tanto, são necessárias teorias para subsidiar tais investigações e, em nosso caso, encontramos suporte nos estudos de Leontiev sobre apropriação e nas pesquisas de Sandholtz, Ringstaff e Dwyer sobre a apropriação tecnológica, complementados pelos estudos de Puentedura.

Na próxima seção discutimos esses conceitos. 


\section{APROPRIAÇÃO E APROPRIAÇÃO TECNOLÓGICA}

Consideramos apropriação como sendo o ato de tornar seu, fazer-se dono ou apossar-se de algo. Assim, definimos apropriação como sendo o processo de integrar algo à maneira de ser de cada indivíduo. Trata-se de um processo que é "o resultado de uma atividade efetiva do indivíduo em relação aos objetos e fenômenos do mundo circundante, criados pelo desenvolvimento da cultura humana” (Leontiev, 2004, p. 290).

Partimos do pressuposto que o processo de apropriação ocorre de forma concomitante com o de construção de conceitos, o que significa considerar que conforme vai se apropriando de algo o indivíduo vai paulatinamente construindo novos esquemas mentais e conhecimentos.

Em relação à apropriação tecnológica, pesquisas pioneiras empreendidas por Sandholtz et al. (1997) no ACOT Project (Apple Classrooms of Tomorrow) apontaram que o processo de apropriação tecnológica por professores é gradual, ele não ocorre automaticamente ou imediatamente logo que o ser humano começa a usar a tecnologia para ensinar. Os pesquisadores identificaram estágios nesse processo de apropriação que vão desde um domínio operacional e técnico dos recursos pelos professores até um estágio intermediário de inserção da tecnologia no ensino, sem grande alteração metodológica da prática pedagógica anterior sem o uso da tecnologia digital, até o estágio final no qual o docente recria a prática pedagógica.

Estudos, tais como os de Vieira (2013), corroboram a existência de um processo gradual de apropriação tecnológica.

\section{GÊNESE INSTRUMENTAL}

Rabardel (1995), baseado na ideia de esquema definido por Piaget, desenvolveu a Abordagem Instrumental que auxilia o entendimento das açôes do sujeito no processo de apropriação de um instrumento. Essa teoria pode subsidiar a análise dos processos de apropriação tecnológica. Ela explica que um artefato informático se torna um instrumento para o indivíduo por meio da gênese instrumental num processo de instrumentação (as condições de artefato a ação do sujeito) e de instrumentalização (adaptação do artefato para o uso é feito).

Para o autor, a palavra "artefato" se refere a qualquer objeto, material ou simbólico, projetado para uma determinada finalidade (um mapa, um software, um computador, um tablet, a linguagem algébrica, a linguagem geométrica etc.). Por outro lado, a palavra “instrumento" refere-se a um misto do artefato propriamente dito e dos esquemas de utilização desenvolvidos pelo usuário.

A Gênese Instrumental é o processo progressivo de construção do instrumento a partir do uso de um artefato por um indivíduo, durante uma atividade para um determinado propósito (Rabardel, 1999). Ao começar a usar um artefato, o indivíduo constrói esquemas próprios de utilização e, com isso, passa a modificar seus esquemas mentais para o uso do artefato para a atividade que se propóe 
desenvolver. Trata-se de um processo progressivo através da atividade do indivíduo ao longo do tempo. O processo da gênese instrumental inclui os artefatos e o próprio sujeito com seus esquemas de utilização na atividade, seus conhecimentos e seu modo de trabalho. Esse processo de gênese instrumental tem duas dimensões indissociáveis: a instrumentalização e a instrumentação.

A Instrumentalização é o processo de diferenciação de um artefato por meio do qual cada usuário se apropria do artefato. É concernente à ação do sujeito sobre o artefato. Instrumentação é o processo pelo qual potencialidades e restrições de um artefato condicionam a ação (como o instrumento modela as estratégias do usuário). A instrumentação ocorre quando o sujeito utiliza o artefato de maneira mediada se apropriando e adaptando os esquemas de utilização. Ela apresenta uma evolução dos esquemas de utilização, assim como a assimilação de artefatos novos aos esquemas já constituídos.

Estudiosos sobre a gênese instrumental, tais como Tapan (2006), alertam que para o professor de matemática ensinar com tecnologia é necessária uma dupla gênese: Instrumentação técnica -construir instrumentos para as tarefas matemáticas e Instrumentação didática- construir os instrumentos para ensinar matemática.

Uma vez consideradas as bases teóricas para a construção de conhecimentos profissionais, outra questão que nos instigou a pesquisar foi a de: Como um individuo mobiliza seus conbecimentos para ensinar matemática com tecnologia?

Entramos então no terreno das competências profissionais e discutimos a seguir a competência digital, necessária (mas não suficiente) para lecionar matemática com tecnologia.

\section{COMPETÊNCIA DIGITAL}

Competências são aqui definidas como uma combinação de conhecimentos, aptidóes e atitudes adequadas que são mobilizadas pelo indivíduo para resolver situações contextuais. Nesse sentido seguimos Perrenoud (1999, p. 15), para o qual "competências são determinadas pela capacidade de mobilizar um conjunto de recursos cognitivos (conhecimentos de conteúdo, princípios elementares, processos etc.) conforme as necessidades, de modo a resolver adequadamente situaçóes-problema que se apresentam ao indivíduo.

As competências podem ser identificadas funcionalmente ou estruturalmente. Pela funcionalidade, a competência do indivíduo é identificada por meio da sua produção e da resolução satisfatória de tarefas. Do ponto de vista estrutural, identifica-se um “espaço” mental proveniente da combinação ordenada de componentes, sejam eles cognitivos ou não.

As competências se manifestam na ação. Elas se desenvolvem por meio da ação e da interação com outros indivíduos, tanto em contextos formais (escolas) como não formais (família, empresas etc.). Cada competência é formada por um conjunto de habilidades mobilizadas para a execução de uma ação, numa área específica de conhecimento. 
O Conselho da União Europeia, em 2006, listou oito competências essenciais ao cidadão no século XXI. São as necessárias a todos os indivíduos para o desenvolvimento pessoal, para exercer cidadania ativa, para a inclusão social e para o emprego (Comissão das Comunidades Europeias, 2006). O Quadro de Referência apresentado no Anexo do documento recomenda para os europeus o desenvolvimento das competências de: comunicação na língua materna; comunicação em línguas estrangeiras; em matemática e as básicas em ciências e tecnologia; a digital; a de aprender a aprender; as sociais e cívicas; o espírito de iniciativa e o espírito empresarial; e a sensibilidade e as expressóes culturais. São elementos constitutivos dessas competências: "Pensamento crítico, criatividade, espírito de iniciativa, resolução de problemas, avaliação de riscos, tomada de decisóes e gestão construtiva dos sentimentos" (Comissão das Comunidades Europeias, 2006).

Entre as competências essenciais listadas está a competência digital. A Comissão Europeia indicou para as nações de todo o mercado comum europeu a premência em incentivar o desenvolvimento nos cidadãos de conhecimentos para o uso eficiente das tecnologias digitais.

Competência digital envolve a utilização segura e crítica das tecnologias da sociedade da informação (TSI) no trabalho, nos tempos livres e na comunicação. Ela é sustentada pelas competências em TDIC, tais como, o uso do computador para obter, avaliar, armazenar, produzir, apresentar e trocar informações e para comunicar e participar em redes de cooperação via Internet. Ela exige uma boa compreensão e sólidos conhecimentos da natureza, do papel que desempenham e das oportunidades que oferecem as TSI em situações do quotidiano: tanto na vida pessoal e social como no trabalho. Nesses conhecimentos incluem-se as principais aplicações informáticas como processadores de texto, folhas de cálculo, bases de dados, armazenamento e gestão de informação, e a compreensão das oportunidades e dos riscos potenciais da Internet e da comunicação por meios electrónicos (correio eletrônico, ferramentas de rede) para o trabalho, os tempos livres, a partilha de informação e a colaboração em rede, a aprendizagem e a investigação (Carretero et al., 2017).

A competência digital implica também uma compreensão do potencial das TSI para apoiar a criatividade e a inovação, e a consciência das questóes ligadas à validade e à fiabilidade da informação disponível e aos princípios jurídicos e éticos ligados ao uso interativo das TSI. Entre as aptidões necessárias contam-se: capacidade de investigar, coligir e processar informação e usá-la de maneira crítica e sistemática, avaliando a pertinência e distinguindo o real do virtual, mas reconhecendo as ligaçóes.

Os indivíduos devem ser capazes de utilizar as ferramentas para produzir, apresentar e compreender informações complexas, e de aceder, pesquisar e usar serviços baseados na Internet. Deverão também ser capazes de usar as TSI para apoiar o pensamento crítico, a criatividade e a inovação. O uso das TSI exige uma atitude crítica e refletida face à informação disponível e um uso responsável dos meios interativos.

A União Europeia tem, por meio do Joint Research Centre (JRC) desde 2005, se debruçado sobre a questão da aprendizagem e desenvolvimento de competências para a era digital tendo realizado diversos estudos e publicações sobre o tema. 
Para os educadores e professores é essencial desenvolver a competência digital e compreender como desenvolver tal competência nos alunos. A Comissão Europeia lançou, em 2017, o documento intitulado: European Framework for the Digital Competence of Educators: DigCompEdu, no qual apresentou o Quadro Europeu para o desenvolvimento da competência digital dos educadores na Europa. O termo educador é usado no documento para indicar o profissional ou qualquer indivíduo envolvido em ensino e que necessita de um conjunto de "competências digitais específicas para a sua profissão de modo a ser capazes de aproveitar o potencial das tecnologias digitais para melhorar e inovar a educação" (Lucas \& Moreira, 2018, p. 8).

O documento se propóe a subsidiar as naçóes a impulsionarem o desenvolvimento da competência digital dos educadores, oferecendo um quadro de referência que considera as competências profissionais, as pedagógicas e as de promoção da aprendizagem. Considerando os diferentes aspectos das atividades profissionais dos educadores, as competências foram distribuídas em seis áreas, a saber: (a) envolvimento profissional; (b) recursos digitais; (c) ensino e aprendizagem; (d) avaliação; (e) capacitação dos aprendentes; e (f) promoção da competência digital dos aprendizes. Nessas áreas se distribuem as 22 competências necessárias aos educadores (ver Figura 3).

\section{Figura 3}

As competências e suas ligaçôes no DigCompEdu (Lucas e Moreira, 2018, p. 16)

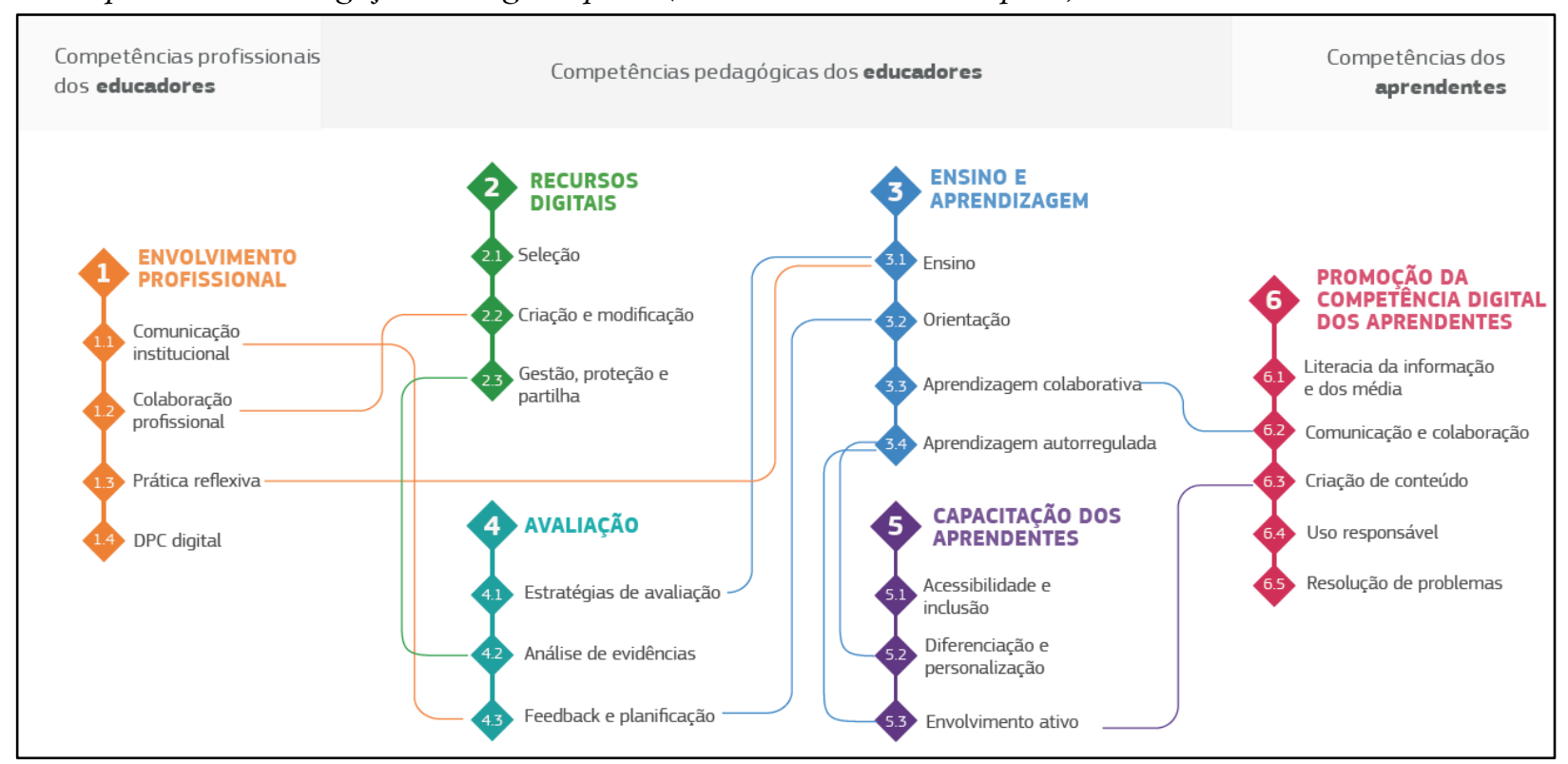

Essa é a síntese dos aportes teóricos que subsidiaram as pesquisas empreendidas por nosso grupo. 


\section{CONCLUSÕES}

A partir dessa gama de pesquisas, listamos nossas principais conclusóes, ou seja, o que aprendemos ao longo do caminho. Nos processos formativos para impulsionar o conhecimento profissional docente (e o TPACK), é necessário:

1. Desenvolver os conhecimentos específicos de matemática, pois sem eles o uso da tecnologia digital fica muito limitada;

2. Desenvolver conhecimentos pedagógicos - discutir possibilidades para ensinar com tecnologia digital e levar o professor a vivenciar na sua prática o uso da tecnologia;

3. Desenvolver conhecimentos tecnológicos -o processo de apropriação depende de qual tecnologia está sendo enfocada;

4. Respeitar o processo de apropriação tecnológica de cada indivíduo e procurar impulsioná-lo.

Em relação à apropriação tecnológica, nossos estudos indicam que o processo de apropriação tecnológica é afetado por fatores emocionais, depende de como o professor lida com desafios, de como se predispóe a aprender e a reconstruir conhecimentos de modo a inserir as TDIC na sua prática pedagógica.

Em relação à instrumentação técnica e didática:

1. Inicialmente o professor utiliza a tecnologia digital para "passar a limpo" a aula;

2. As tarefas e propostas aprendidas na formação são "replicadas” na sala de aula;

3. Para promover avanços, tem sido muito relevante levar os professores a assistirem vídeos de aulas com a tecnologia e discutirem a mediação, as tarefas propostas, o papel dos alunos na aula e como o aluno raciocinou para a realização de cada tarefa proposta, ou seja, promover o desenvolvimento do olhar profissional (profesional noticing);

4. Utilizar a tecnologia digital e outros recursos didáticos para o desenvolvimento de metodologias de ensino nas quais o aluno seja um participante ativo.

Em conclusão, integrar as tecnologias digitais disponíveis ao ensino para promover a aprendizagem dos alunos não é um processo simples. Isso demanda para o docente novas aprendizagens e reconstrução de conhecimentos de modo a construir o conhecimento pedagógico tecnológico do conteúdo (TPACK).

Finalizando, apontamos perspectivas para próximas investigações:

1. Pesquisas no segmento dos anos iniciais de escolaridade com a utilização de recursos tecnológicos para o ensino, uma vez que temos poucas pesquisas até então, em nosso país; 
2. Pesquisas que envolvam pensamento computacional e programação (ex. uso do a linguagem de programação Scratch);

3. Pesquisas em processos de formação na modalidade EaD e em modelos híbridos;

4. Pesquisas sobre Avaliação - como promover "trilhas para aprendizagem" individualizadas com uso de bancos de dados, disponibilizadas em plataformas;

5. Construção por professores de trajetórias de aprendizagem com tecnologia;

6. Construçãao por professores de sequências didáticas eletrônicas;

7. Desenvolver estudos sobre a base teórica -Olhar profissional (Llinares, 2013; Mason, 2002) -compreender o pensamento matemático do aluno, em situaçóes de ensino que envolvam as tecnologias digitais;

8. Desenvolver estudos sobre o TPACK acoplado ao Modelo SAMR (Puentedura, 2013).

Enfim, a jornada de educadores e pesquisadores para a integração das TDIC aos processos de ensino e de aprendizagem de Matemática continua e se faz cada vez mais necessária para contemplar as características dos alunos da Geração Z.

\section{ACLARATORIAS}

La autora no tiene conflictos de interés que declarar. El artículo ha sido financiado con recursos propios de la autora.

\section{REFERENCIAS}

Carretero, S., Vuorikari, R., \& Punie, Y. (2017). DigComp 2.1: the digital competence framework for citizens with eight proficiency levels and examples of use. Joint Research Centre - European Comission. http://europa.eu/!Yg77Dh

Comissão das Comunidades Europeias (2006). Recomendação do Parlamento Europeu e do Conselho, de 18 de Dezembro de 2006, sobre as competências essenciais para a aprendizagem ao longo da vida. Jornal Oficial L 394 de 30.12.2006 da União Europeia (COM 2006/962/EC). https://eurlex.europa.eu/legal-content/PT/TXT/?uri=CELEX:32006H0962

Dias, F. A. S. (2010). Educação online e formação continuada de educadores: uma investigação sobre interação em curso para professores de matemática do Ensino Médio [dissertação de mestrado, Universidade Bandeirante de São Paulo]. Repositório Institucional UNIAN.

https://repositorio.pgsskroton.com//handle/123456789/3555 
Dias, F. A. (2015). Integração de tecnologias digitais ao curriculo de matemática: um estudo do projeto Aula Interativa [tese de doutorado, Universidade Anhanguera de São Paulo]. Repositório Institucional UNIAN. https://repositorio.pgsskroton.com//handle/123456789/31990

Figueiredo, S. A. (2015). Formação inicial de professores e a integração da prática como componente curricular na disciplina de matemática elementar [tese de doutorado, Universidade Anhanguera de São Paulo]. Repositório Institucional UNIAN. https://repositorio.pgsskroton.com//handle/123456789/32022

Koehler, M. J., \& Mishra, P. (2009). What is technological pedagogical content knowledge? Contemporary Issues in Technology and Teacher Education, 9(1), 60-70.

Leontiev, A. (2004). O desenvolvimento do psiquismo. $2^{\text {a }}$ edición. Centauro.

Llinares, S. (2013). Professional noticing: a component of the mathematics teacher's professional practice. Sisyphus - Journal of Education, 1(3), 76-93. https://doi.org/10.25749/sis.3707

Lobo da Costa, N. M. (2004). Formação de professores para o ensino da matemática com a informática integrada à prática pedagógica: exploração e análise de dados em bancos computacionais [tese de doutorado, Pontifícia Universidade Católica de São Paulo]. https://www.academia.edu/s/d720ff9ad1

Lobo da Costa, N. M., Prado, M. B., \& Galvão, M. E. (2015). Mathematics teaching and digital technologies: a challenge to the teacher's everyday school life. Quaderni di Ricerca in Didattica: Matematica, 25(suplemento 2). Proceedings CIEAEM 67, 279-286. http://math.unipa.it/ grim/CIEAEM\%2067_Proceedings_QRDM_Issue\%2025_Suppl.2.pdf

Lobo da Costa, N. M., Prado, M. B., \& Dias, M. A. (2017). Investigative tasks: possibilities to develop teachers' technological pedagogical content knowledge. Quaderni di Ricerca in Didattica: Matematica, 27(suplemento 2). Proceedings CIEAEM 69, 235-239. http://math.unipa.it/ grim/CIEAEM\%2069_Pproceedings_QRDM_Issue\%2027,\%20Suppl.2.pdf

Lucas, M., \& Moreira, A. (2018). DigCompEdu: quadro europeu de competência digital para educadores. UA.

Marchi, V. D. (2011). Um grupo de estudos de professores de matemática e a exploração de conteúdos de geometria euclidiana em WebQuest [dissertação de mestrado, Universidade Anhanguera de São Paulo]. Repositório Institucional UNIAN. https://repositorio.pgsskroton.com//handle/123456789/3675 
FORMACIÓN DE PROFESORES DE MATEMÁTICAS Y EL CONOCIMIENTO NECESARIO...

Mason, J. (2002). Researching your own practice: the discipline of noticing. Routledge Falmer. https://doi.org/10.4324/9780203471876

Mishra, P., \& Koehler, M. J. (2006). Technological pedagogical content knowledge: a framework for teacher knowledge. Teachers college record, 108(6), 1017-1054. https://doi.org/10.1111/j.1467$\underline{9620.2006 .00684 . x}$

Muraca, F. S. (2011). Educação continuada do professor de matemática: um contexto de problematização desenvolvido por meio de atividades exploratório-investigativas envolvendo geometria espacial de posição [dissertação de mestrado, Universidade Bandeirante de São Paulo]. Repositório Institucional UNIAN. https://repositorio.pgsskroton.com//handle/123456789/3557

Nonato, K. J., \& Lobo da Costa, N. M. (2020a). Licenciatura actual en matemáticas: la urgencia de la enseñanza con tecnologías digitales de información y comunicación. Revista Paradigma, 41(Extra 2), 633-667. https://doi.org/10.37618/PARADIGMA.1011-2251.0.p633-667.id930

Nonato, K. J.; \& Lobo da Costa, N. M. (2020b, novembro). Licenciatura em Matemática da Universidade Federal da Grande Dourados: elos entre o projeto pedagógico e o conbecimento tecnológico e pedagógico do conteúdo [comunicação em congresso]. 2 Seminário de Pesquisa e PósGraduação Stricto Sensu, Londrina, Brasil. https://eventos.pgsskroton.com/anais/trabalho/127

Oliveira, C. R. (2014). Tecnologias no ensino de matemática: uma investigação no projeto "Aula Interativa” [dissertação de mestrado, Universidade Anhanguera de São Paulo]. Repositório Institucional UNIAN. https://repositorio.pgsskroton.com/handle/123456789/3529

Oliveira, W. A. (2017). Tecnologias digitais na formação continuada: situaçôes de ensino articulando geometria e funçôes [dissertação de mestrado, Universidade Anhanguera de São Paulo]. Repositório Institucional UNIAN. https://repositorio.pgsskroton.com//handle/123456789/12180

Orfão, R. B. (2012). Professores de matemática em um grupo de estudos: uma investigação sobre o uso de tecnologia no ensino de funçôes trigonométricas [dissertação de mestrado, Universidade Anhanguera de São Paulo]. Repositório Institucional UNIAN. https://repositorio.pgsskroton.com//handle/123456789/3651

Patriarca, F. H. (2016). Contribuiçôes do programa M@tmidias para a integração de tecnologia às aulas de trigonometria no Ensino Médio [dissertação de mestrado, Universidade Anhanguera de São Paulo]. Repositório Institucional UNIAN. https://repositorio.pgsskroton.com/handle/123456789/21800 
Pereira Filho, A. D. (2018). Formação continuada de professores do Ensino Médio para uma aula investigativa no ensino de probabilidade [tese de doutorado, Universidade Anhanguera de São Paulo]. Repositório Institucional UNIAN. https://doi.org/10.23864/cpp.v3i1.249

Perrenoud, P. (1999). Construir as competências desde a escola. Artes Médicas.

Poloni, M. Y. (2015). Formação continuada de professores de matemática - recursos didáticos para o ensino de trigonometria [tese de doutorado, Universidade Anhanguera de São Paulo]. Repositório Institucional UNIAN. https://repositorio.pgsskroton.com//handle/123456789/32060

Ponte, J. P. (1998). Da formação ao desenvolvimento prof issional. Em Actas do ProfMat 98 (pp. 27 44). APM.

Prensky, M. (2010). Teaching digital natives partnering for real learning. CA Corwin.

Prieto G., J. L., \& Ortiz, J. (2019). Saberes necesarios para la gestión del trabajo matemático en la elaboración de simuladores con GeoGebra. Bolema: Boletim de Educação Matemática, 33(65), 1276-1304. https://doi.org/10.1590/1980-4415v33n65a15

Puentedura, R. R. (2013, 29 de maio). Paths to technology integration: SAMR E TPCK in context [workshop presentation]. Information and Communication Technologies (ICT) Management and Leadership Conference, Canberra, Australia. http://www.hippasus.com/rrpweblog/archives/2013/05/29/Paths'ToTechnologyIntegration.pdf

Rabardel, P. (1995). Les hommes et les technologies une approche cognitive des instruments contemporains. Armand Colin.

Rabardel, P. (1999). Éléments pour une approche instrumentale en didactique des mathématiques. Em M. Bailleul (Ed.), Actes de la Xème Ecole d'Été en Didactiques des Mathématiques (pp. 202-213). IUFM de Caen.

Sandholtz, J. H., Ringstaff, C., \& Dwyer, D. C. (1997). Teaching with technology: creating. StudentCentered Classrooms. Teachers College.

Shulman, L. S. (1986). Those who understand: knowledge growth in teaching. Educational Researcher, 15, 4-14. https://doi.org/10.3102/0013189X015002004

Shulman, L. S. (1987). Knowledge and teaching: foundations of the new reform. Harvard Educational Review, 57, 1-22. https://doi.org/10.17763/haer.57.1.j463w79r56455411 
Silva, W. O. (2018). Formação continuada: um estudo sobre integração de tecnologia digital para ensinar poliedros [tese de doutorado, Universidade Anhanguera de São Paulo]. Repositório Institucional UNIAN. https://repositorio.pgsskroton.com//handle/123456789/32039

Tapan, M. S. (2006). Différents types de savoirs mis en oeuvre dans la formation initiale d'enseigants de mathématiques à l'intégration de technolgoies de géométrie dynamique [tese de doutorado, Université Joseph-Fourier - Grenoble I]. Hal Theses. https://tel.archives-ouvertes.fr/tel$\underline{00133569 /}$

Vieira, E. R. (2013). Grupo de estudos de professores e a apropriação de tecnologia digital no ensino de geometria: caminhos para o conhecimento profissional [tese de doutorado, Universidade Bandeirante de São Paulo]. Repositório Institucional UNIAN. https://repositorio.pgsskroton.com//handle/123456789/3476

\section{Cómo citar este artículo:}

Lobo da Costa, N. M. (2021). Formação de professores de Matemática e os conhecimentos necessários à docência com tecnologias digitais. Revista Venezolana de Investigación en Educación Matemática (REVIEM), 1(2), e202103. https://doi.org/10.54541/reviem.v1i2.30 
Usted es libre para Compartir — copiar y redistribuir el material en cualquier medio o formato - y Adaptar el documento — remezclar, transformar y crear a partir del material - para cualquier propósito, incluso para fines comerciales, siempre que cumpla la condición de:

Atribución: Usted debe dar crédito a la obra original de manera adecuada, proporcionar un enlace a la licencia, e indicar si se han realizado cambios. Puede hacerlo en cualquier forma razonable, pero no de forma tal que sugiera que tiene el apoyo del licenciante o lo recibe por el uso que hace de la obra.

$\underline{\text { Resumen de licencia - Texto completo de la licencia }}$ 